\title{
RESTRIÇÃO AO ACESSO À INTERNET E A OFENSA AO PACTO SOBRE OS DIREITOS CIVIS E POLÍTICOS: UMA ANÁLISE A PARTIR DA PONDERAÇÃO
}

\section{ESTRICTED ACCESS TO THE INTERNET AND THE OFFENSE TO THE COVENANT ON CIVIL AND POLITICAL RIGHTS : AN ANALYSIS FROM CONSIDERATION}

\section{RESUMO}

A ONU considera o acesso à internet um direito humano e entende que restringir de qualquer forma a conexão da população à rede mundial de computadores fere a liberdade de expressão e informação. Alguns países, porém, editaram leis que limitam o uso do espaço virtual alegando questões de ordem pública, como segurança nacional e proteção do próprio indivíduo. Neste sentindo, buscar-se-á através do método dedutivo de investigação científica, aferir se a produção legislativa estrangeira é legítima, vale dizer, se é compatível com os preceitos de tratados internacionais.

Palavras-chave: Restrição à internet, Direitos humanos, Ponderação

\section{ABSTRACT}

The UN considers Internet access a human right and understand that restrict in any way the population's connection to the World Wide Web hurts freedom of expression and information. Some countries, however, edited laws that limit the use of the virtual space on the grounds of public policy issues, such as national security and the individual's own protection. In this feeling, it will be sought through the deductive method of scientific research, assess whether the foreign legislation is not legitimate, that is, it is compatible with the precepts of international treaties

Keywords: Keywords: restriction on the internet, Human rights, Weighing

\footnotetext{
${ }^{1}$ Mestre em Ciências Jurídicas pelo Centro Universitário de Maringá - Unicesumar, Paraná, (Brasil). Especialista em Direito do Estado pela Universidade Estadual de Londrina - UEL, Paraná. E-mail: fernandonavarrovince@ gmail.com ${ }^{2}$ Doutor em Direito Constitucional pela Universidade Federal do Paran, Curitiba, Paraná. Presidente Executivo do Instituto de Direito Constitucional e Cidadania - IDCC. E-mail: tutortreinamento@ gmail.com
} 


\section{INTRODUÇÃO}

Em junho de 2012, o Conselho de Direitos Humanos da Organização das Nações Unidas (ONU) editou a Resolução A/HRC/20/L.13, denominada de Human Rights Council on Human Rights on the Internet, cujo conteúdo reconhece o acesso à Internet como direito humano. Mais precisamente, o principal organismo internacional considera que a conexão do indivíduo à rede mundial traduz desdobramento do princípio da liberdade de expressão e informação.

É notório que a Internet se tornou nos dias atuais, mecanismo essencial a permitir o exercício de direitos básicos como liberdade de expressão e opinião, nos termos da Convenção sobre Direitos Civis e Políticos. Indispensável à comunicação das pessoas, se mostra também imprescindível a realização de tarefas básicas do dia a dia. Por mais estranho que se apresente, não mais se concebe uma vida plena, sem a utilização das novas tecnologias, redes sociais, aplicativos, correios eletrônicos, etc. É por meio destes avanços que o homem moderno se perfaz.

Considera-se, assim, que os direitos do homem são históricos, caracterizados por lutas em defesa de novas liberdades em face de velhos poderes, e nascidos de modo gradual, não todos de uma vez e nem de uma vez por todas (BOBBIO, 2004, p. 05). Dito de outro modo, o direito é fruto da sociedade e seus carecimentos, e a sociedade moderna, globalizada, exige o reconhecimento como direito essencial do homem o acesso as novas tecnologias, notadamente a internet.

Nesse sentido, afirma Manuel Castells (2009, p. 100) que a internet "é a base da comunicação em nossas vidas, para trabalho, conexões pessoais, informações, entretenimento, serviços públicos e religião”, abrangendo, assim, todas as dimensões do humano (ética, política, artística, econômica, religiosa e científica).

A ONU não ficou alheia e essa situação fática e tratou de promover a proteção da liberdade de opinião/expressão também no âmbito virtual. Segundo seu entendimento, desconectar as pessoas, independente do motivo, é crime que atenta contra os direitos humanos.

Esta circunstância reforma e redesenha a liberdade de expressão e comunicação. De acordo com Zygmunt Bauman:

Em primeiro lugar, num planeta atravessado por 'auto-estradas da informação', nada que acontece em alguma parte dele pode de fato, ou 
ao menos potencialmente, permanecer do 'lado de direitos humanos fora' do intelectual. Não há terra nulla, não há espaço em branco no mapa mental, não há terra nem povo desconhecidos, muito menos incognoscíveis. (2007, p. 11)

Se o mundo virtual é uma reprodução do "mundo real", se a internet passa a ser vista e utilizada como um meio para a propagação de conteúdos e de discursos, é necessária a proteção dos direitos fundamentais e humanos em seu ambiente.

Com a massificação do uso das novas mídias, o bloqueio indevido e o controle exagerado ou ilegal de informações afetam diretamente a liberdade de expressão. Neste sentido, Frank Michelman (2007, p. 5) observa que a concepção material de liberdade de expressão significaria que "as oportunidades e capacidades comunicativas de alguns membros da sociedade não estão sendo injustamente oprimidas por atos e decisões, não só do Estado, mas de outros agentes da sociedade".

Destarte pode-se conceber que o acesso à plataforma virtual é um direito individual, pois decorre ou é um desdobramento de outros direitos básicos do homem como desenvolvimento da personalidade, exercício da cidadania, acesso a informação, liberdade de expressão. Independente do meio - ambiente virtual ou não - as liberdades individuais inerentes a pessoa devem ser respeitadas. Ou seja, a transposição para a Internet, não retira a essencialidade e necessidade de proteção.

Pois bem, mesmo considerando os enormes e incontáveis benefícios advindos da utilização da rede mundial, inegável que a mesma traz consigo perigos como o terrorismo, discriminações racial, religiosa e sexual, pornografia infantil, xenofobia, intolerâncias, dentre outras práticas nocivas.

A regra é a liberdade dentro do espaço virtual, porém, existem hipóteses onde o acesso pode ser reduzido ou condicionado. Entretanto, a preocupação estatal em prevenir ou diminuir a incidência dessas mazelas contemporâneas, não pode legitimar a adoção de práticas abusivas que terminem por servir de escora para a censura, prática nefasta e incompatível com os ideais democráticos modernos.

Com base nessas transformações decorrentes das novas tecnologias da informação e da comunicação, este artigo traz reflexões sobre as limitações ao uso do espaço virtual promovida por países que alegam questões de ordem pública, como segurança nacional e proteção do próprio indivíduo, frente a uma possível violação de preceitos de tratados internacionais. 


\section{MECANISMOS GLOBAIS DE GARANTIA À LIBERDADE DE EXPRESSÃO E INFORMAÇÃO}

Os tratados internacionais visam harmonizar interesses que pertencem a toda a sociedade internacional.

A Declaração Universal dos Direitos Humanos de 1948, reconhece em seu artigo 19 que todo indivíduo "[...] tem direito à liberdade de opinião e de expressão, o que implica o direito de não ser inquietado pelas suas opiniões e o de procurar, receber e difundir, sem consideração de fronteiras, informações e ideias por qualquer meio de expressão".

No mesmo norte, o Pacto Internacional sobre Direitos Civis e Políticos determina em seu artigo 19:

1. ninguém poderá ser molestado por suas opiniões.

2. Toda pessoa terá direito à liberdade de expressão; esse direito incluirá a liberdade de procurar, receber e difundir informações e ideias de qualquer natureza, independentemente de considerações de fronteiras, verbalmente ou por escrito, em forma impressa ou artística, ou por qualquer outro meio de sua escolha.

3. O exercício do direito previsto no parágrafo 2 do presente artigo implicará deveres e responsabilidades especiais. Consequentemente, poderá estar sujeito a certas restrições, que devem, entretanto, ser expressamente previstas em lei e que se façam necessárias para:

a) assegurar o respeito dos direitos e da reputação das demais pessoas; b) proteger a segurança nacional, a ordem, a saúde ou a moral pública. (MINISTÉRIO DA JUSTIÇA. Pacto internacional sobre direitos civis e políticos, 2015).

Assim, ao desconectar as pessoas, atenta-se contra os direitos humanos, especialmente no que consiste o art. 19. 3 do Pacto Internacional de Direitos Civis e Políticos de 1966.

O direito à liberdade de expressão consagrado nos principais instrumentos internacionalmente de abrangência global, influenciaram outros tratados sobre o tema. Nessa trilha, a Convenção Americana de Direitos Humanos (Pacto de San José da Costa Rica) de 1969, instrumento regional de proteção aos direitos do indivíduo, reafirmam em seu artigo 13 a liberdade de pensamento e de expressão, nos seguintes termos:

1. Toda pessoa tem o direito à liberdade de pensamento e de expressão. Esse direito inclui a liberdade de procurar, receber e difundir informações e ideias de qualquer natureza, sem considerações de fronteiras, verbalmente ou por escrito, ou em forma impressa ou artística, ou por qualquer meio de sua escolha. 
2. O exercício do direito previsto no inciso precedente não pode estar sujeito à censura prévia, mas a responsabilidades ulteriores, que devem ser expressamente previstas em lei e que se façam necessárias para assegurar:

a) o respeito dos direitos e da reputação das demais pessoas;

b) a proteção da segurança nacional, da ordem pública, ou da saúde ou da moral públicas.

3. Não se pode restringir o direito de expressão por vias e meios indiretos, tais como o abuso de controles oficiais ou particulares de papel de imprensa, de frequências radioelétricas ou de equipamentos e aparelhos usados na difusão de informação, nem por quaisquer outros meios destinados a obstar a comunicação e a circulação de ideias e opiniões.

4. A lei pode submeter os espetáculos públicos a censura prévia, com o objetivo exclusivo de regular o acesso a eles, para proteção moral da infância e da adolescência, sem prejuízo do disposto no inciso 2.

5. A lei deve proibir toda propaganda a favor da guerra, bem como toda apologia ao ódio nacional, racial ou religioso que constitua incitamento à discriminação, à hostilidade, ao crime ou à violência. (grifou-se) (CIDH. Convenção Americana sobre Direitos Humanos, 2015).

Reafirmando os direitos humanos e liberdades fundamentais consagrados na Declaração Universal dos Direitos Humanos e nos tratados internacionais de direitos humanos pertinentes, incluindo o Pacto Internacional sobre os Direitos Civis e Políticos e o Pacto Internacional sobre os Direitos Econômicos, Sociais e Culturais, o Conselho de Direitos Humanos da Organização das Nações Unidas (ONU) editou, em 2012, a Resolução A/HRC/20/L.13, denominada de The promotion, protection and enjoyment of human rights on the Internet ${ }^{1}$, que reconhece o acesso à internet como garantia à a liberdade de expressão e informação.

Em síntese, o documento internacional aduz que:

1. Os mesmos direitos que as pessoas têm offline também devem ser protegidos online, em particular a liberdade de expressão, que é aplicável independentemente de fronteiras e por qualquer meio de sua escolha, de acordo com os artigos 19 da Declaração Universal dos Direitos Humanos e o Pacto Internacional sobre os Direitos Civis e Políticos.

\footnotetext{
${ }^{1}$ São os países que se fizeram presente da Resolução: Argélia, Argentina, Austrália, Áustria, Azerbaijão, Bélgica, Bolívia, Bósnia e Herzegovina, Brasil, Bulgária, Canadá, Chile, Costa Rica, Costa do Marfim, Croácia, Chipre, República Checa, Dinamarca, Djibuti, Egito, Estónia, Finlândia, França, Geórgia, Alemanha, Grécia, Guatemala, Honduras, Hungria, Islândia, Índia, Indonésia, Irlanda, Itália, Letónia, Líbia, Liechtenstein, Lituânia, Luxemburgo, Maldivas, Malta, Mauritânia, México, Mônaco, Montenegro, Marrocos, Holanda, Nigéria, Noruega, Palestina, Peru, Polônia, Portugal, Qatar, República da Moldávia, República da Coreia, Roménia, Sérvia, Eslováquia, Eslovénia, Somália, Espanha, Suécia, a antiga República Jugoslava da Macedónia, Timor -Leste, Tunísia, Turquia, Ucrânia, Reino Unido da GrãBretanha e Irlanda do Norte, Estados Unidos da América e Uruguai.
} 
2. Reconhece a natureza global e aberta da Internet como uma força motriz para acelerar o progresso rumo ao desenvolvimento nas suas diversas formas;

3. Exorta todos os Estados a promover e facilitar o acesso à Internet $\mathrm{e}$ de cooperação internacional que visa o desenvolvimento dos meios de comunicação e informação e instalações de comunicações em todos os países;

4. Incentiva procedimentos especiais a tomar em conta estas questões dentro de seus mandatos existentes, conforme o caso;

5. Decide continuar a consideração da promoção, proteção e gozo dos direitos humanos, incluindo o direito à liberdade de expressão, na Internet e em outras tecnologias, bem como da forma como a Internet pode ser uma ferramenta importante para o desenvolvimento e para a o exercício dos direitos humanos, de acordo com o seu programa de trabalho. $^{2}$

Com efeito, a Resolução consolida a ideia de que a Internet é um dos mais poderosos instrumentos do século XXI para ampliar a transparência na conduta dos poderosos, permitir o acesso à informação, facilitar a participação cívica ativa na construção de sociedades democráticas, vez que desempenha papel primordial na mobilização de populações em clames por justiça, igualdade e melhor respeito pelos direitos humanos. ${ }^{3}$

\section{NORMAS ESTRANGEIRAS QUE RESTRINGEM OU CONTROLAM O ACESSO A INTERNET}

Se de um lado há mecanismos internacionais de proteção do homem garantem sua liberdade de pensamento e de expressão, de outro verificou-se, nos últimos anos,

\footnotetext{
2 "1. Affirms that the same rights that people have offline must also be protected online, in particular freedom of expression, which is applicable regardless of frontiers and through any media of one's choice, in accordance with articles 19 of the Universal Declaration of Human Rights and the International Covenant on Civil and Political Rights; 2. Recognizes the global and open nature of the Internet as a driving force in accelerating progress towards development in its various forms; 3.Calls upon all States to promote and facilitate access to the Internet and international cooperation aimed at the development of media and information and communications facilities in all countries; 4. Encourages special procedures to take these issues into account within their existing mandates, as applicable; 5. Decides to continue its consideration of the promotion, protection and enjoyment of human rights, including the right to freedom of expression, on the Internet and in other technologies, as well as of how the Internet can be an important tool for development and for exercising human rights, in accordance with its programme of work." (GENERAL ASSEMBLY, 2012, p. 2)

3 "The Special Rapporteur believes that the Internet is one of the most powerful instruments of the 21 st century for increasing transparency in the conduct of the powerful, access to information, and for facilitating active citizen participation in building democratic societies. Indeed, the recent wave of demonstrations in countries across the Middle East and North African region has shown the key role that the Internet can play in mobilizing the population to call for justice, equality, accountability and better respect for human rights." (GENERAL ASSEMBLY, 2011, p. 4)
} 
um boom na adoção, por parte dos governos ao redor do mundo, de tecnologia de vigilância e legislações criadas com o objetivo de amordaçar informações online.

$\mathrm{Na}$ China, a censura à Internet é evidente e recorrente. Para vigiar o grande número de usuários, o partido comunista gasta bilhões de dólares por ano no controle das informações que circulam pela rede. Manter blogs ou postar vídeos criticando o governo é considerado crime passível de prisão. O governo controla os assuntos proibidos por meio de filtros, que encontram palavras-chave ligadas a movimentos democráticos, como "revolta", "massacre", "direitos humanos" ou "movimento estudantil".

O referido país oriental opera um avançado sistema de filtragem denominado "Projeto Escudo Dourado" e conhecido como o Grande Firewall da China. O sistema pode conduzir buscas por páginas de web novas e censurar seu acesso em tempo real. Também pode conduzir buscas de conteúdo subversivo em blogs e impedir usuários de visitá-los. Recentemente, esse Estado rejeitou as críticas da ONU sobre o projeto de lei que limita acesso à internet. Segundo o governo chinês, o projeto de lei prevê que o governo possa "limitar o acesso à internet para manter a ordem pública, especificamente quando ocorrerem eventos imprevistos de massas", como aconteceu há seis anos na região do Xinjiang, de maioria muçulmana, quando quase 200 pessoas morreram no verão de 2009, durante conflitos étnicos que, segundo as autoridades chinesas, foram instigados através das redes sociais por organizações separatistas sedeadas fora da China. Desde então, o acesso ao Facebook e ao Twitter está bloqueado no país. Procurando despolemizar essa possibilidade, um jornal do Partido Comunista Chinês (PCC) afirmou que "o corte da internet acontecerá raramente e como último recurso", reconhecendo que essa medida "também afetará os interesses do público". O alto- comissário da Organização das Nações Unidas para os Direitos Humanos, Zeid Ra'ad al Hussein, criticou o projeto de lei, considerando-o "ambíguo" e suscetível de "apertar o controle das autoridades chinesas sobre a sociedade civil”. (AGÊNCIA BRASIL, 2016)

Todavia, não é somente a China que tradicionalmente censura o acesso da população à rede. Todos os anos, a organização Reporters Without Borders, que se dedica a promover a liberdade de expressão e a segurança para o trabalho de jornalistas, divulga um relatório com a lista de países que reprimem a liberdade de expressão pela internet, intimidam bloggers, e realizam a vigilância de seus cidadãos. Estes países são denominados de "enemies of the internet" (inimigos da internet). 
No relatório publicado em 2014 demonstrou que alguns países se mantêm na lista, enquanto outros buscam caminhos para sair dela. Dois países que se destacam positivamente no relatório são Tunísia e Myanmar, ambos buscaram alternativas para não censurar a internet e a liberdade de expressão por meio dela. (REPORTERS WITHOUT BORDERS, 2014)

$\mathrm{Na}$ primeira categoria de países listados no relatório estão os que mais reprimem o uso da internet com a implementação de vigilância sobre a liberdade de expressão pela web ou nos quais não foi verificado nenhum progresso nos últimos anos. São eles: Cuba, Coréia do Norte, China, Iran, Arábia Saudita, Vietnã, Belarus, Bahrain, Turcomenistão, Síria.

Outros países são destacados pelo relatório como Bangladesh, onde quatro bloggers e o secretário das ONG de direitos humanos, foram presos em 2013 sob alegação de violação da Information and Communication Technology Act de 2006, na qual as definições de crimes digitais são extremamente ampla e vaga, e inclui "publicar informação falsa, obscena ou difamar de forma eletrônica”. (REPORTERS WITHOUT BORDERS, 2014, p. 7).

A Gâmbia promoveu em 2013, alterações na principal lei que limita a liberdade de informação, a Information and Communications Act. Uma delas consiste em determinar que "difusão de notícias falsas contra o governo ou funcionários públicos" deve ser punida com até 15 anos de prisão ou uma multa equivalente a 64.000 euros. (REPORTERS WITHOUT BORDERS, 2014, p. 7).

O Vietnã dispõe em seu Código Penal (artigos 79 e 88) o crime de "infringir a segurança nacional" e "propaganda contra a República Socialista do Vietnã", e desde 2013, prevê a restrição ao uso de blogs e redes sociais para a "divulgação" ou "compartilhamento" de informação "pessoal", proibindo efetivamente a partilha de conteúdos relacionados com notícias ou interesse geral. (REPORTERS WITHOUT BORDERS, 2014, p. 7).

O relatório destaca também para uma relação de novos países que passaram a fazer parte da lista dos "inimigos da internet". Esse grupo de nações composto por Rússia, Paquistão, Estados Unidos, Reino Unido, Índia e Etiópia, têm tomado medidas duras para restringir ou monitorar os cidadãos via da internet. (REPORTERS WITHOUT BORDERS, 2014)

Na Rússia, até muito recentemente, o governo não censurava diretamente a internet, preferindo empregar estratégias sutis para controlar o discurso online. A 
mudança ocorreu em 2012, quando se aprovou uma lei permitindo a criação de uma lista negra nacional de websites. Hoje, essa lista negra continua a crescer, enquanto o governo continua a procurar novas formas de limitar a liberdade de expressão pela web.

No Paquistão, apesar da oposição significativa no interior do país que buscam evitar a repressão, a Autoridade Paquistão Telecomunicações continua a adicionar sites à sua lista negra.

Os Estados Unidos apareceram pela primeira vez na lista do Reporters Without Borders. Apesar de não censurar conteúdo online, o que levou o país a ser incluído na listagem foi a severa vigilância da Agência Nacional de Segurança ${ }^{4}$, inclusive em outros países.

O Reino Unido é chamado pelo Reporters Without Borders como o "campeã mundial de vigilância" por suas estratégias de espionar indivíduos em todo o mundo.

A Índia, apesar de censurar certos tipos de discurso, nunca havia sido incluída na lista do Reporters Without Borders, porém, nos últimos anos, o governo indiano promulgou novas leis para limitar o discurso on-line, limitando, significativamente, a liberdade de expressão.

Por fim, a Etiópia, considerado o país africano que mais tem restringido o uso da internet nos últimos anos, bloqueando serviços, sentenciando blogueiros a longas penas de prisão, e promulgação de leis para bloquear conteúdo online. Em 2014, a Electronic Frontier Foundation (EFF) entrou com uma ação acusando o governo etíope de instalação de spyware no dispositivo de um cidadão americano de origem etíope. ${ }^{5}$ Em um caso semelhante, a Privacy International apresentou uma denúncia penal alegando o uso de FinSpy no dispositivo de um residente do Reino Unido. ${ }^{6}$

\footnotetext{
${ }^{4}$ Em meados de setembro de 2013, baseado em documentos fornecidos por Snowden à Greenwald, revelou-se que a Agência de Segurança Nacional (NSA) espionou a Petrobrás com fins de beneficiar os americanos nas transações com o Brasil.

${ }^{5}$ Um cidadão americano que vive em Maryland, Estados Unidos, processou o governo etíope por infectar seu computador com spyware secreto, monitorando toda a sua família por meses. Kidane nasceu e viveu sua infância na Etiópia, porém pediu asilo aos Estados Unidos há vinte anos, e desde então é cidadão. A Electronic Frontier Foundation (EFF) entrou com uma ação no Tribunal Federal de Washington, DC, alegando que o governo da Etiópia, usando malwares de vigilância conhecido como FinSpy, ilegalmente grampeou e invadiu a privacidade de Kidane, um cidadão americano e que teve seus direitos violados nos Estados Unidos. Essencialmente, o malware assumiu computador de Kidane e secretamente enviou cópias de suas atividades, incluindo Skype, pesquisas na web, indicações de sites visitados dentre outra atividade, ao governo etíope. (ELECTRONIC FRONTIER FOUNDATION, 2015)

${ }^{6}$ Depois de sofrer anos de assédio persistente, da violência e vigilância nas mãos de seu governo opressor, Tadesse Kersmo e sua esposa escaparam Etiópia, onde tinham sido politicamente ativos durante anos. Alguns anos depois de terem recebido asilo na no Reino Unido (2009) eles descobriram que haviam sido rastreados pelo computador através de um Trojan que é parte de um kit chamado FinFisher. (PRIVACY INTERNATIONAL, 2014)
} 
Alguns países como Turquia, Jordânia e Marrocos ficaram fora do índice dos “inimigos da internet” em 2014, mas deveria ter sido incluído.

Em 2013, a Turquia promulgou a legislação que impunha restrições ao uso da internet. Desde então, aproximadamente 37 mil websites foram impedidos de operar por mandatos judiciais e ordens administrativas de bloqueio. (NAÇÕES UNIDAS NO BRASIL, 2014) O país tem estado sob os holofotes dos defensores dos direitos humanos, uma vez que em 2012, o Tribunal Europeu dos Direitos Humanos ${ }^{7}$ constatou que a Turquia violou o direito dos cidadãos e a liberdade de expressão, garantidos na Convenção Europeia dos Direitos Humanos, ao bloquear sites do Google. ${ }^{8}$

A Jordânia, apesar dos protestos locais e oposição internacional, deu início em junho de 2013 a proibição de mais de 300 sites de notícias que recusou ou não se registrar no Departamento de Imprensa e Publicações.

No Marrocos, a prisão do jornalista Ali Anouzla em setembro de 2013 quando foi processado por "atentar contra a integridade territorial", "apologia" e "incitação ao terrorismo" após postar em seu site Lakome2 o um link de um vídeo da al-Qaeda ameaçando a segurança de Marrocos, e que havia sido publicado no site espanhol $E l$ País. Tal fato denunciou a fragilidades na garantia à liberdade de imprensa naquele país, e despertou a atenção organização Reporters Without Borders. (REPORTERS WITHOUT BORDERS, 2014)

Na Bielorrússia, entrou em vigor em 2012 uma nova legislação sobre a internet, que restringe o acesso a sites catalogados em uma lista. A justificativa da lei é impedir o acesso a sítios de caráter pornográfico, violento ou extremista.

Os opositores do presidente Alexandre Lukashenko, considerado pela União Europeia o último ditador do Velho Continente, afirmam tratar-se de uma manobra para controlar os dissidentes. Os fornecedores de acesso à internet, os cybercafés e todos os

\footnotetext{
7 O Tribunal Europeu dos Direitos Humanos foi criado em Estrasburgo pelos Estados membros do Conselho da Europa em 1959 para lidar com as alegadas de violações da Convenção Europeia dos Direitos do Homem de 1950.

${ }^{8}$ O caso "Ahmet Yildirim c. Turquie" diz respeito a decisão de um tribunal de bloquear o acesso ao "Google Sites" que hospedava um site cujo dono era acusado em uma ação penal por insultar a memória de Atatürk. Esta ação de bloqueio teve o efeito de impedir igualmente o acesso a todos os outros sites hospedados pelo servidor. O Tribunal observou que a justiça turca, antes de banir o serviço de hospedagem, deveria ter verificado se não existiam outras maneiras de impedir o acesso apenas ao site ofensor, ou ter consultado a Google e avisado sobre o conteúdo que a empresa estava hospedando, o que não foi feito. Por conta da violação, o Tribunal Europeu determinou à Turquia o pagamento de 7,5 mil euros (cerca de R 20 mil) de indenização por danos morais para o usuário que reclamou. (COUR EUROPÉENNE DES DROITS DE L'HOMME, 2012)
} 
locais de acesso público à internet vão ter de registar os dados relativos aos seus clientes e de os conservar durante um ano. (EURONEWS, 2012)

Os países, em sua grande maioria, alegam ordem pública, como segurança nacional e proteção do próprio indivíduo, para a adoção de medidas limitadoras ou proibitivas do uso do espaço virtual em seus territórios.

Assim, ao mesmo tempo em que o acesso à internet traduz um direito humano moderno, também colide com outros direitos já existentes, e a restrição a esse preceito somente será legítima quando fundamentada e se o valor protegido for, no caso examinado, superior ao valor subjugado. Ou seja, por se tratar de colisão de direitos humanos fundamentais (direito humano fundamental x segurança nacional) a resposta virá por meio da técnica da ponderação.

Por serem geralmente estruturados como princípios, em inúmeras situações, há choque de valores. Então, como resolver o problema da colisão de liberdades individuais, se no plano abstrato eles possuem a mesma posição na hierarquia legislativa? A solução deve vir à luz do caso concreto, através da técnica jurídica da ponderação de interesses.

\section{PONDERAÇÃO COMO MÉTOdO PARA EQUACIONAR COLISÃo DE DIREITOS HUMANOS}

Apesar da relevância ímpar que os direitos humanos desempenham nas ordens jurídicas democráticas, eles podem ser relativizados. E a necessidade de proteção de outros bens jurídicos diversos, também revestidos de envergadura constitucional, pode justificar excepcionais restrições (SARMENTO, 2004, p. 293).

Para Alexandre de Moraes (2011, p. 61), “[...] os direitos e garantias fundamentais não são ilimitados, uma vez que encontram seus limites nos demais direitos igualmente consagrados pela Carta Magna (princípio da relatividade)”. Quando colidir com outro direito fundamental, a suavização poderá acontecer.

Oportuno aqui consignar, que a doutrina atual divide as colisões em: colisão em sentido impróprio e colisão em sentido autêntico. Na colisão em sentido impróprio, o exercício de um determinado direito fundamental entra em colisão com outros bens constitucionalmente protegidos, como os bens jurídicos da comunidade tais como "saúde pública", "patrimônio cultural”, "defesa nacional” e "família" (CANOTILHO, 2003, p. 1229). Já a colisão autêntica de direitos fundamentais, ocorre quando o "[...] 
exercício de um direito fundamental por parte de seu titular colide com o exercício do direito fundamental por parte de outro titular". Esta colisão pode ser entre direitos fundamentais diferentes ou entre os aspectos negativo e positivo de um mesmo direito, como no famoso caso ocorrido na Alemanha conhecido como "decisão sobre o crucifixo"9 (NOVELINO, 2014, p. 379).

No caso em exame, estamos diante de uma colisão de direitos fundamentais em sentido impróprio, vez que estão a se chocar, de um lado o direito humano de acesso a internet, e de outro, por exemplo, a segurança nacional (terrorismo), proteção integral da criança (pedofilia), dignidade da pessoa humana (racismo), dentre outros.

A resposta virá por meio da técnica da ponderação ou sopesamento. Por outras palavras, para aferir se a restrição de acesso à internet imposta pela norma local é legítima, será necessário ponderar. Verificar qual direito fundamental deve prevalecer, será o melhor para aquela hipótese específica.

Para o mundo do direito, a ponderação representa um mecanismo para se extrair qual é a melhor opção jurídica a seguir. Trata-se, mais precisamente no campo constitucional, de recurso colocado à disposição do intérprete para que ele avalie qual o direito fundamental deverá prevalecer perante as situações de conflito. Por seu intermédio, procura-se estabelecer o peso relativo de cada um dos princípios contrapostos e escolher o mais apropriado para solucionar o impasse.

Os valores de cada um não determinam o que deve ser melhor, mas o que é melhor. Por isso, dependem de apreciação subjetiva o que não impede sua aplicação racional. $\mathrm{Na}$ colisão entre dois princípios, não se questiona o que é devido, apenas o que é, naquele momento, o melhor (CAMBI, 2011, p. 89).

O que se visualiza é que, por meio da ponderação, é instaurada uma relação de precedência justificada que informa porque um princípio deve prevalecer sobre o outro. As condições pelas quais um princípio prevalece representam o pressuposto fático de uma regra que expressa a consequência jurídica do princípio precedente (ALEXY, 2008, p. 94).

\footnotetext{
${ }^{9}$ Tal caso ocorrera quando em 1995 um grupo de mórmons da Baviera inconformado com a obrigação imposta pelo Estado de se sujeitarem, durante o período de aulas, a "aprender sobre o pálio da cruz" ajuizou uma ação na qual o pedido era a retirada dos crucifixos colocados nas escolas públicas alemãs. Apesar de a maioria germânica ser católica naquela região, ao analisar a colisão entre a liberdade religiosa de caráter negativo dos não cristãos e a liberdade de manifestação religioso dos cristãos dentro do âmbito das instituições estatais, o Tribunal Federal Constitucional proibiu o uso dos crucifixos nas escolas públicas, levando em consideração entre outros aspectos, a neutralidade do Estado alemão (LEITE, web).
} 
Quando os princípios se contrapõem em um caso concreto, há que se apurar o peso - nisso consistindo a ponderação - que apresentam nesse mesmo caso, tendo presente que, se apreciados em abstrato, nenhum desses princípios em choque ostenta primazia definitiva sobre o outro. Nada impede, assim, que, em caso diverso, com outras características, o princípio antes preterido venha a prevalecer (MENDES; BRANCO, 2015, p. 112).

Assim, pelo mecanismo da ponderação, o operador do direito examinará a hipótese apresentada, e ao identificar os princípios em atrito, escolherá qual terá mais peso e deverá obter vantagem no caso concreto. Esse procedimento será realizado, conforme orientação da melhor doutrina, de forma fracionada, por meio de algumas etapas.

\subsection{A Ponderação como Processo de Aplicação da Proporcionalidade}

O balanceamento de direitos humanos fundamentais pode ser estruturado em três etapas, sendo as duas primeiras de preparação e a terceira, a ponderação propriamente dita. A primeira consiste na identificação das normas colidentes e seu agrupamento conforme a direção para a qual apontam. Em seguida, devem ser analisadas as circunstâncias do caso concreto, bem como suas repercussões. Após essas duas etapas preparatórias, deve-se atribuir o peso relativo aos elementos sob choque e estabelecer a intensidade da preferência de cada grupo de normas (BARCELLOS, 2005, p. 93).

Por possuírem posição equivalente na escala valorativa constitucional - mesmo grau hierárquico - somente diante das circunstâncias específicas da ação examinada será possível verificar o peso de cada princípio envolvido e a intensidade de sua preferência. A relação de preferência de um princípio sobre o outro é condicionada, vale dizer, a condições diversas. Assim, o resultado pode ser diferente em situações englobando os mesmos direitos. Isso ocorre em razão do caráter diferenciado dos princípios (mandamentos de otimização), entre os quais não existe uma relação absoluta de preferência e cujas ações e situações às quais se referem não são passíveis de quantificação (DIMOULIS; MARTINS, 2011, p. 167).

Ao propor a utilização da teoria dos princípios como a melhor forma de solucionar as colisões de direitos fundamentais, Alexy esclarece que o sopesamento 
pode ser formulado com o seguinte enunciado: “[...] quanto mais intensa se revelar a intervenção em um dado direito fundamental, maiores hão de se revelar os fundamentos justificadores dessa intervenção". De acordo com o jusfilósofo alemão, a ponderação propriamente dita se desenvolve em três planos: (1) definição da intensidade da intervenção; (2) análise da importância dos fundamentos justificadores da intervenção; e (3) realização da ponderação em sentido restrito (ALEXY apud DIMOULIS; MARTINS, 2011, p. 168).

Sendo assim, o exercício comum do balanceamento como fórmula para resolver colisões de normas constitucionais é justificada, se considerados os seguinte argumentos: (i) a existência de uma sociedade plural; (ii) suas Constituições e leis que refletem a pluralidade de valores e fazem uso intensivo de expressões gerais, cujo sentido pode variar justamente em função de concepções valorativas ou ideológicas; (iii) a ascensão política do judiciário como espaço de discussão alternativo àquele dos órgãos eleitos, tem-se a ampliação progressiva do espaço próprio da interpretação jurídica, considerando ainda que cada intérprete dispõe de suas próprias convicções valorativas e políticas, não é de surpreender que sejam diagnosticadas tantos conflitos normativos e que a ponderação seja frequentemente empregada (BARCELLOS, 2005, p.17).

A doutrina socorre-se, então, do método de ponderação de bens ou interesses, no qual o operador do direito examinará a hipótese apresentada, identificando os princípios em atrito, e posteriormente escolherá qual terá mais peso e deverá obter vantagem no caso. Neste ponto insere-se a grande questão do sopesamento: invariavelmente uma norma constitucional será descumprida. O julgador deverá decidir qual norma "vale menos" e essa restrição somente poderá ser admitida se for proporcional. Deve-se indagar, dessa maneira, não apenas sobre a admissibilidade constitucional da restrição eventualmente fixada (reserva legal), mas também sobre a compatibilidade das restrições estabelecidas com o princípio da proporcionalidade (MENDES; BRANCO, 2015, p. 330).

Como invariavelmente uma norma constitucional será preterida, o hermeneuta deverá decidir, no caso que lhe for levado à apreciação, qual lei fundamental vale menos. Diante da gravidade e importância da escolha - afastamento de um princípio constitucional - a restrição somente será legítima (adequada, necessária e proporcional), e por conseguinte, justa, ser for pautada em consonância com o princípio da proporcionalidade. 
O juízo de ponderação une-se ao princípio da proporcionalidade, que exige que o sacrifício de um direito seja útil para a resolução do problema, que não haja outro meio menos danoso para atingir o resultado desejado e que seja proporcional em sentido estrito, isto é, que o ônus imposto ao sacrificado não sobreleve o benefício que se pretende obter com a solução (MENDES; BRANCO, 2015, p. 263). Opera-se então, a proporcionalidade como uma estrutura complexa de raciocínio jurídico, cujo sentido é delimitado por metanormas (normas que tratam da aplicação de outras normas) mais concretas e específicas (BUSTAMANTE, 2005, p. 247).

Dessa forma, o princípio da proporcionalidade, conhecido por limite dos limites, atua como ferramenta indispensável para impingir a legitimidade e a adequação das normas com os ditames da justiça e da razão. Todavia, o exercício do referido método interpretativo não pode ser realizado de forma crua, pouco elaborada e com base em critérios subjetivos. O referido postulado possui dimensões que condicionam a sua aplicação, e eliminam o perigo da subjetividade. Essas dimensões são concretizadas através da observação dos subprincípios da adequação, necessidade e proporcionalidade em sentido estrito.

\subsection{Os Subprincípios da Adequação, Necessidade e Proporcionalidade em Sentido Estrito}

Visando aprimorar e definir critérios para o sopesamento de valores, a doutrina jurídica estabelece a existência de três elementos ou subprincípios do princípio da proporcionalidade: adequação, necessidade e a proporcionalidade em sentido estrito. Luiz Virgílio Afonso da Silva, ao se referir à desnecessidade de análise acumulativa dos três subprincípios, advertiu que:

A real importância dessa ordem fica patente quando se tem em mente que a aplicação da regra da proporcionalidade nem sempre implica a análise de todas as suas três sub-regras. Pode-se dizer que tais subregras relacionam-se de forma subsidiária entre si. Essa é uma importante característica, para a qual não se tem dado a devida atenção. A impressão que muitas vezes se tem, quando se mencionam as três sub-regras da proporcionalidade, é que o juiz deve sempre proceder à análise de todas elas, quando do controle do ato considerado abusivo. Não é correto, contudo, esse pensamento. É justamente na relação de subsidiariedade acima mencionada que reside a razão de ser da divisão em sub-regras. Em termos claros e concretos, com subsidiariedade quer-se dizer que a análise da necessidade só é exigível se, e somente se, o caso já não tiver sido resolvido com a análise da adequação; e a análise da 
proporcionalidade em sentido estrito só é imprescindível, se o problema já não tiver sido solucionado com as análises da adequação e da necessidade. Assim, a aplicação da regra da proporcionalidade pode esgotar-se, em alguns casos, com o simples exame da adequação do ato estatal para a promoção dos objetivos pretendidos. Em outros casos, pode ser indispensável a análise acerca de sua necessidade. Por fim, nos casos mais complexos, e somente nesses casos, deve-se proceder à análise da proporcionalidade em sentido estrito (SILVA, 2002, p.12).

Por adequação entende-se que devem ser utilizadas medidas apropriadas para alcançar a finalidade prevista no mandamento. Deve-se perguntar se o meio escolhido foi pertinente para atingir o resultado almejado. Se não, desrespeitou-se o princípio da proporcionalidade e a escolha não poderá obter guarida do Poder Judiciário. Exige-se assim, que a opção adotada seja apta a alcançar os objetivos pretendidos. O aplicador da norma examinará se o meio é "simplesmente inadequado", "objetivamente inadequado", "manifestamente inadequado ou desnecessário", "fundamentalmente inadequado, ou se "com sua utilização o resultado pretendido pode ser estimulado" (MENDES; BRANCO, 2015, p. 332).

Completando as lições de Mendes, esclarecendo um suposto equívoco de tradução literária, Luiz Virgílio da Silva acrescenta que adequação não se resume a averiguar se os meios corretos foram usados, in verbis:

Esses conceitos de adequação não são, contudo, os mais corretos. A causa do problema está na tradução imprecisa da decisão. A sentença em alemão seria melhor compreendida se se traduzisse o verbo fördern, usado na decisão, por fomentar, e não por alcançar, como faz Gilmar Ferreira Mendes, porque, de fato, o verbo fördern não pode ser traduzido por alcançar. Fördern significa fomentar, promover. Adequado, então, não é somente o meio com cuja utilização um objetivo é alcançado, mas também o meio com cuja utilização a realização de um objetivo é fomentada, promovida, ainda que o objetivo não seja completamente realizado (SILVA, 2002, p.14).

Tem-se que a ação é adequada quando sua utilização resulta no fim pelo qual a finalidade legítima tenha sido alcançada ou, no mínimo, fomentada.

Em relação ao segundo subprincípio, a necessidade, exige-se que a decisão escolhida seja a que produz menor prejuízo para o cidadão e para a coletividade. Não podendo ser excessiva, nem tampouco insuficiente. Nem de mais, nem de menos. Em outros termos, o meio não será necessário se o objetivo almejado puder ser alcançado com a adoção de medida que se revele, a um só tempo, adequada e menos onerosa (MENDES; BRANCO, 2015, p. 333). Um ato estatal que limita um direito fundamental 
é somente necessário caso a realização do objetivo perseguido não possa ser promovida, com a mesma intensidade, por meio de outro ato que limite, em menor medida, o direito fundamental atingido (SILVA, 2002). Logo, será desnecessária a conduta que desconsiderou outro meio menos prejudicial de solucionar o caso.

Assim sendo, forçoso concluir que, ainda que uma medida que limite um direito humano fundamental seja adequada e necessária para promover outro valor, isso não demonstra, por si só, que ela deve ser considerada como proporcional. Necessário é esse terceiro e derradeiro exame, que consiste em um sopesamento entre a intensidade da restrição ao direito atingido e a importância da realização do direito que com ele colide e que fundamenta a adoção da medida restritiva.

Portanto, vislumbra-se que a proporcionalidade em sentido estrito está conectada intimamente e intensamente à técnica da ponderação, e a ação produzida deve trazer a noção de justa medida, sendo que os caminhos percorridos tenham razoável correlação com o objetivo pretendido, permitindo assim, um equilíbrio entre os valores afetados.

Destarte, pode-se concluir que, em que pese determinação da ONU para se evitar, em qualquer caso, a restrição de acesso a internet, este direito humano do cidadão poderá sim ser minimizado legitimamente, se a limitação ocorrer para salvaguardar outro direito fundamental considerado, após aplicação da técnica da ponderação, de maior peso na hipótese concreta.

\section{CONSIDERAÇÕES FINAIS}

O artigo prometeu uma reflexão sobre a legitimidade dos atos normativos internacionais que restringem o acesso à Internet, mais precisamente buscou verificar se limitar a conexão do indivíduo à rede mundial de computadores afronta o Pacto sobre Direitos Civis e Políticos.

Para honrar o compromisso assumido, a primeira parte do estudo destinou-se a demonstrar que a ONU considera o acesso do cidadão à Internet como direito humano, pois, entende que essa prerrogativa traduz desdobramento do princípio da liberdade de expressão e informação. Nesse sentido, constatou-se que o mencionado organismo internacional prega que a restrição, independente da forma como se dê, ofende os preceitos fundamentais da pessoa. 
Posteriormente, numa segunda etapa, o trabalho apresentou normas estrangeiras que controlam o acesso à Internet. Vieram à lume dispositivos legais editados ao redor do mundo que têm como objetivo comum amordaçar ou ocultar informações online. Escorados em temas de relevância extrema, como segurança nacional, combate a pedofilia e pornografia infantil, prevenção do racismo, os governos produzem leis que monitoram o cidadão no ambiente virtual.

As perguntas centrais eram: Essas normas que restringem o acesso à Internet são legítimas? Elas ofendem o Pacto sobre Direitos Civis e Políticos no tocante a liberdade de expressão e informação? Qualquer forma de restrição é ilegal?

Resposta veio na terceira parte do artigo.

Apontando a técnica da ponderação - mecanismo de decisão jurídica a ser utilizados para decidir casos difíceis, envolvendo direitos fundamentais, onde a subsunção se mostre insuficiente - concluiu-se que o direito humano de acesso a web, assim como os demais direitos desse naipe, não é absoluto, e por consequência, seu exercício está sujeito a limites. Embora a ONU determine que se evite, em qualquer caso, a restrição de acesso à Internet, esse direito do cidadão poderá sim ser minimizado legitimamente, se a limitação ocorrer para salvaguardar outro direito fundamental considerado, após o balanceamento, de maior peso na hipótese concreta. Logo, a norma estrangeira será legitima se a restrição for razoável e fundamentada na proteção de outros valores constitucionais. De igual forma, não haverá ofensa ao Pacto sobre Direitos Civis e Políticos, se a limitação contida na lei for necessária, adequada e proporcional. Em arremate, não se pode generalizar e considerar toda e qualquer limitação como ofensiva e inaceitável, vez que, a relativização do acesso poderá extraordinariamente ocorrer se racionalmente justificada.

\section{REFERÊNCIAS}

AGÊNCIA BRASIL. China rejeita críticas da ONU a projeto de lei que limita acesso à internet. Disponível em: <http://agenciabrasil.ebc.com.br/>. Acesso em: 20.mar.2016.

ALEXY, Robert. Teoria dos direitos fundamentais. São Paulo: Malheiros, 2008.

BARCELlOS, Ana Paula. Ponderação, Racionalidade e Atividade Jurisdicional. São Paulo: RENOVAR, 2005

BAUMAN, Zygmunt. Tempos Líquidos. Rio de Janeiro: Jorge Zahar, 2007. 
BOBBIO, Norberto. A Era dos Direitos. Tradução Carlos Nelson Coutinho. 18. ed. Rio de Janeiro: Elsevier, 2004.

BUSTAMANTE, Thomas. Argumentação contra legem: a teoria do discurso e a justificação jurídica nos casos mais difíceis. Rio de Janeiro: Renovar, 2005.

CANOTILHO, Joaquim José Gomes. Direito constitucional e teoria da constituição. 7. ed. Coimbra: Almedina, 2003.

CASTELLS, Manuel. Communication Power. New York: Oxford University Pres, 2009.

CIDH. Convenção Americana sobre Direitos Humanos. Assinada na Conferência Especializada Interamericana sobre Direitos Humanos, San José, Costa Rica, em 22 de novembro de 1969. Disponível em: 〈http://www.cidh.org>. Acesso em: 25 set. 2015.

COUR EUROPÉENNE DES DROITS DE L'HOMME. Affaire Ahmet Yildirim $c$. Turquie (Requête n. 3111/10). Disponível em: <http://hudoc.echr.coe.int/eng?i=001115401\#\{"itemid":["001-115401"]\}>. Publicado em: 18 dez. 2012. Acesso em: 07.mar.2016.

DIMOULIS, Dimitri; MARTINS, Leonardo. Teoria geral dos direitos fundamentais. 3. ed. São Paulo: Revista dos Tribunais, 2011.

ELECTRONIC FRONTIER FOUNDATION. Kidane v. Ethiopia. Disponível em: <https://www.eff.org/document/complaint-32>. Publicado em: 15 jul. 2015. Acesso em: 07.mar.2016.

EURONEWS. Bielorrússia: Lei para controlar acesso à internet entra em vigor. Disponível em: < http://pt.euronews.com/2012/01/06/bielorrussia-lei-para-controlaracesso-a-internet-entra-em-vigor/>. Publicado em: 06 jan. 2012. Acesso em: 10.mar.2016.

GENERAL ASSEMBLY. Report of the Special Rapporteur on the promotion and protection of the right to freedom of opinion and expression, Frank La Rue. 16 May 2011. Disponível em: <http://www2.ohchr.org/english/bodies/hrcouncil/docs/17session/A.HRC.17.27_en.pdf $>$. Acesso em: 10.mar.2016.

GENERAL ASSEMBLY. The promotion, protection and enjoyment of human rights on the Internet,29 Jun 2012. Disponível em: <https://documents-ddsny.un.org/doc/UNDOC/LTD/G12/147/10/PDF/G1214710.pdf?OpenElement>. Acesso em: 10.mar.2016.

GOULART, Guilherme Damasio. O impacto das novas tecnologias nos direitos humanos e fundamentais: o acesso à internet e a liberdade de expressão. REDESG / Revista Direitos Emergentes na Sociedade Global. v. 1, n. 1, jan.jun/2012, p. 146-168. 
MENDES, Gilmar Ferreira; BRANCO, Paulo Gustavo Gonet. Curso de Direito Constitucional. 10. ed. São Paulo: Saraiva, 2015.

MICHELMAN, Frank. Relações entre democracia e liberdade de expressão: discussão de alguns argumentos. In: SARLET, Ingo. Wolfgang (org). Direitos Fundamentais, Informática e Comunicação: algumas aproximações. Porto Alegre: Livraria do Advogado, 2007.

MINISTÉRIO DA JUSTIÇA. Pacto internacional sobre direitos civis e políticos. Disponível em: <http://portal.mj.gov.br>. Acesso em: 26 nov. 2015.

MORAES, Alexandre de. Direitos fundamentais: teoria geral, comentários aos arts. $1^{\circ}$ a $5^{\circ}$ da Constituição da República Federativa do Brasil, doutrina e jurisprudência. 9. ed. São Paulo: Atlas, 2011.

NAÇÕES UNIDAS NO BRASIL. Turquia: Nova lei de Internet preocupa escritório de direitos humanos da ONU. Disponível em: <https://nacoesunidas.org/turquia-nova-leide-internet-preocupa-escritorio-de-direitos-humanos-da-onu/>. Publicado em: 14 fev. 2014. Acesso em: 10.mar.2016.

NOVELINO, Marcelo. Manual de Direito Constitucional. 9. ed. São Paulo: Método, 2014.

PRIVACY INTERNATIONAL. Surveillance follows Ethiopian political refugee to the $U K$. Disponível em: 〈https://www.privacyinternational.org/node/416>. Publicado em: 16 fev. 201. Acesso em: 07.mar.2016.

REPORTERS WITHOUT BORDERS. Enemies of the Internet 2014: entities at the heart of censorship and surveillance. Disponível em: <http://12mars.rsf.org/2014en/enemies-of-the-internet-2014-entities-at-the-heart-of-censorship-and-surveillance/>. Acesso em: 10.mar.2016.

SARMENTO, Daniel. Direitos fundamentais e relações privadas. Rio de Janeiro: Lumen Juris, 2004.

SILVA, Luís Virgílio Afonso da. O proporcional e o razoável. In: Revista dos Tribunais, São Paulo, ano 91, n. 798, p. 23-50, abr. 2002. 